\title{
Estimativas de impactos da elevação do nível do mar em 2100 na zona urbana de Caiçara do Norte/RN.
}

Estimates of impacts of sea level rise in 2100 in the urban area of Caiçara do Norte/ RN.

\author{
SILVA $^{1}$, J. P.; AZEVÊDO ${ }^{2}$, J. M. M.; DINIZ ${ }^{3}$, M. T. M.
}

jucyelho@hotmail.com

\begin{abstract}
Resumo
Este artigo traz a tona uma temática que vem sendo discutida no mundo inteiro: elevação do nível do mar. Este fenômeno ocorre de forma naturalmente se observado em escala de tempo mais extensa, entretanto a partir de 1750 , período considerado pré-industrial, o homem começou a contribuir para alterações climáticas globais, através da emissão dos GEE (Gases do Efeito Estufa), e alterando assim a temperatura global o que acarreta no aceleramento da elevação do nível do mar. Desta forma o objetivo desta pesquisa é através de técnicas de geoprocessamento e SIG, usando como base os modelos de previsões do AR5 do IPCC, mostrar as possíveis áreas afetadas pela elevação do nível do mar em parte da zona urbana da cidade de Caiçara do Norte - Rio Grande do Norte para o ano 2100, e desta forma fornecer suporte aos tomadores de decisões responsáveis pela região. Para isto utilizou-se pesquisas bibliográficas, técnicas de geoprocessamento avançado e manuseio de equipamento e softwere de ponta, tais como Estação Total Foif modelo OTS 680 e ArcGis 10.3 respectivamente.
\end{abstract}

Palavras-chave: Elevação do nível do mar; impactos; Caiçara do Norte.

\begin{abstract}
This article brings up an issue that has been discussed worldwide: sea level rise. This phenomenon occurs so naturally observed in longer time scale, however from 1750 , a period considered preindustrial, the man began to contribute to global climate change through the emission of greenhouse gases (GHGs), and thus changing the global temperature which results in accelerating the in sea level rise. Thus the objective of this research is through geoprocessing and GIS, using as a basis the models of the IPCC AR5 forecasts, show the possible areas affected by rising sea level in parts of the urban area of North Caiçara - Rio Grande do Norte for the year 2100, and thus provide support to decision makers responsible for the region. For this we used bibliographical research, technical advanced geoprocessing and handling equipment and state-of softwere such as Estação Total FOIF model OTS 680 and ArcGis 10.3 respectively.
\end{abstract}

Keywords: Sea level rise; impacts; Caiçara do Norte

\section{INTRODUÇÃO}

De acordo com os relatórios do IPCC (Intergovernmental Panel On Climate Change) a partir do ano 1750 considerado período pré-industrial, o homem começou fortemente a contribuir para alterações climáticas globais, através da emissão dos GEE (Gases do Efeito Estufa). Com a alteração do clima consequentemente altera-se o nível médio dos mares.

É de consenso por parte dos cientistas das áreas afins que o nível médio dos mares varia em função do tempo, em escala geológica, proveniente das glaciações e Inter glaciações.

Segundo John A. Church; Peter U. Clark (2013), organizadores do capítulo 13 referente à variação do nível do mar do AR5 (quinto relatório do IPCC), já existem diversos registros de

\footnotetext{
${ }^{1}$ Jucielho Pedro da Silva, Departamento de Geografia /Laboratório de geoprocessamento e geografia fisica, Universidade Federal do Rio Grande do Norte-CERES, Caicó-RN, Brasil.

${ }^{2}$ Júlia Maria Medeiros de Azevêdo, Departamento de Geografia /Laboratório de geoprocessamento e geografia fisica, Universidade Federal do Rio Grande do Norte-CERES, Caicó-RN, Brasil.

${ }^{3}$ Marco Túlio Mendonça Diniz, Departamento de Geografia /Laboratório de geoprocessamento e geografia fisica, Universidade Federal do Rio Grande do Norte- CERES, Caicó-RN, Brasil.
} 
paleoníveis do mar feitos por toda parte do planeta, dentre eles a maioria mostra que o nível médio dos mares já esteve entre $5 \mathrm{~m}$ e 10m acima do nível atual.

Porém com o amento dos GEE na atmosfera aumenta-se a retenção de calor na atmosfera que consequentemente aumenta a temperatura média global, que por sua vez altera toda a dinâmica natural, provocando o derretimento de geleiras, aumentando a evaporação nos continentes e o volume por expansão térmica dos oceanos, contribuindo-se assim para o aumento do nível médio global dos mares.

Segundo Poh Poh Wong; Iñigo J. Losada (2014) organizadores do capítulo 5 do grupo II parte A do AR5 as zonas costeiras de baixa altitude só compõe 2\% da área terrestre do mundo, mas essas regiões contam com $10 \%$ da população mundial cerca de 600 milhões de pessoas, baseado no ano 2000. No Brasil o número de pessoas que residem em zonas costeiras é ainda maior cerca de 26,6\% da população (50,7 milhões) de acordo com o atlas geográfico das zonas costeiras e oceânicas do Brasil (2011).

Com a aceleração do aumento do nível do mar e a grande expansão da população residente em zonas costeiras de forma desordenada e em locais inapropriados, surge a preocupação em estipularem-se, através de modelos estatísticos, os futuros níveis do mar em função do tempo para auxiliar tomadores de decisões a se precaverem em relação a possíveis desastres naturais.

Por tanto, o objetivo dessa pesquisa é através de técnicas de geoprocessamento e SIG (Sistema de Informações Geográfica), usando como base os modelos de previsões do AR5 do IPCC, mostrar as possíveis áreas afetadas pela elevação do nível do mar em parte da zona urbana da cidade de Caiçara do Norte-Rio Grande do Norte para o ano 2100, tendo em vista que essa região já vem sofrendo fortes processos erosivos tais como observado por Tabosa (2006) que constatou que a linha de costa nesta cidade teve um recuo na ordem dos 200m em apenas 21 anos (1967 a 1988) e a zona urbana vem sofrendo constantes alagamentos marinhos em eventos de ressaca marinha como mostra a Figura 01. "O fenômeno ressaca é o aumento do nível do mar provocado pela elevação da maré astronômica e/ou maré meteorológica, acompanhado de ondas com amplitude maior que o normal.” (BITENCOURT; QUADRO; CALBETE, 2002). 


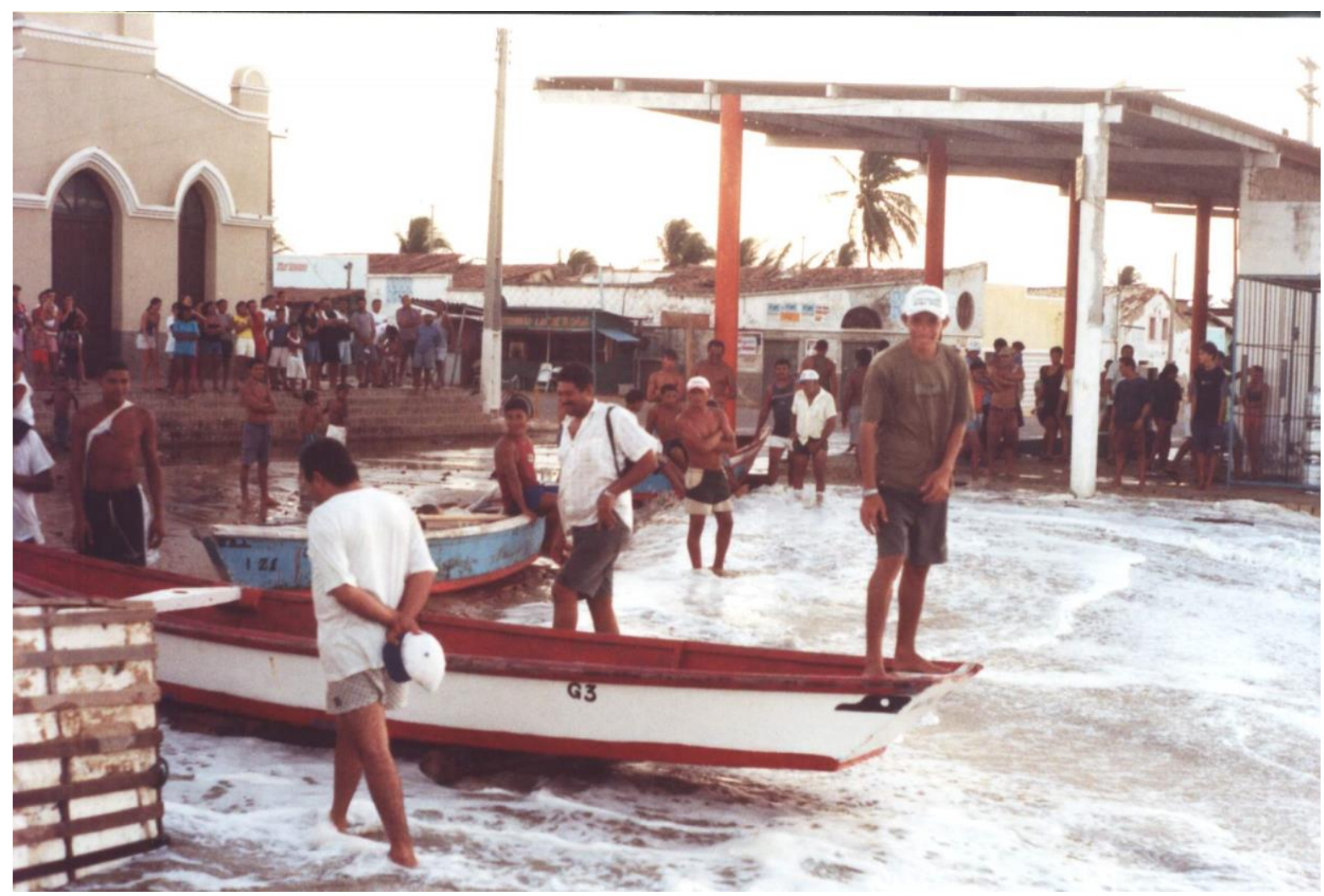

Figura 01. Alagamento em Caiçara do Norte. Fonte: TABOSA, W.F. (2002)

Na Figura 01 observam-se as ondas invadindo a zona urbana da cidade de Caiçara do Norte no mês de fevereiro de 2002, onde a maré atingiu $2.8 \mathrm{~m}$, ressaltando-se que essa é uma região de Mesomaré com amplitude média de $1,01 \mathrm{~m}$ a $3 \mathrm{~m}$ em marés de sizígia segundo o Atlas geográfico das zonas costeiras e oceânicas do Brasil. BIVAR, W; JULIO, de S. M, N. (2011).

O município de Caiçara do Norte pertence à micro região de Macau, fazendo limites com os municípios de São Bento do Norte ao leste, com Galinhos ao oeste, com Jandaíra e Parazinho ao sul, e com o Oceano Atlântico ao norte. O município conta com uma população de 6016 habitantes segundo o senso demográfico do IBGE de 2010 (Instituto Brasileiro de Geografia e Estatística), sendo 5894 residindo na zona urbana e 122 residindo na zona rural. De acordo com planta baixa e mapa de localização (Figura 02) e informações do IBGE 2010 a zona urbana desta cidade conta com 1577 domicílios permanentes. 


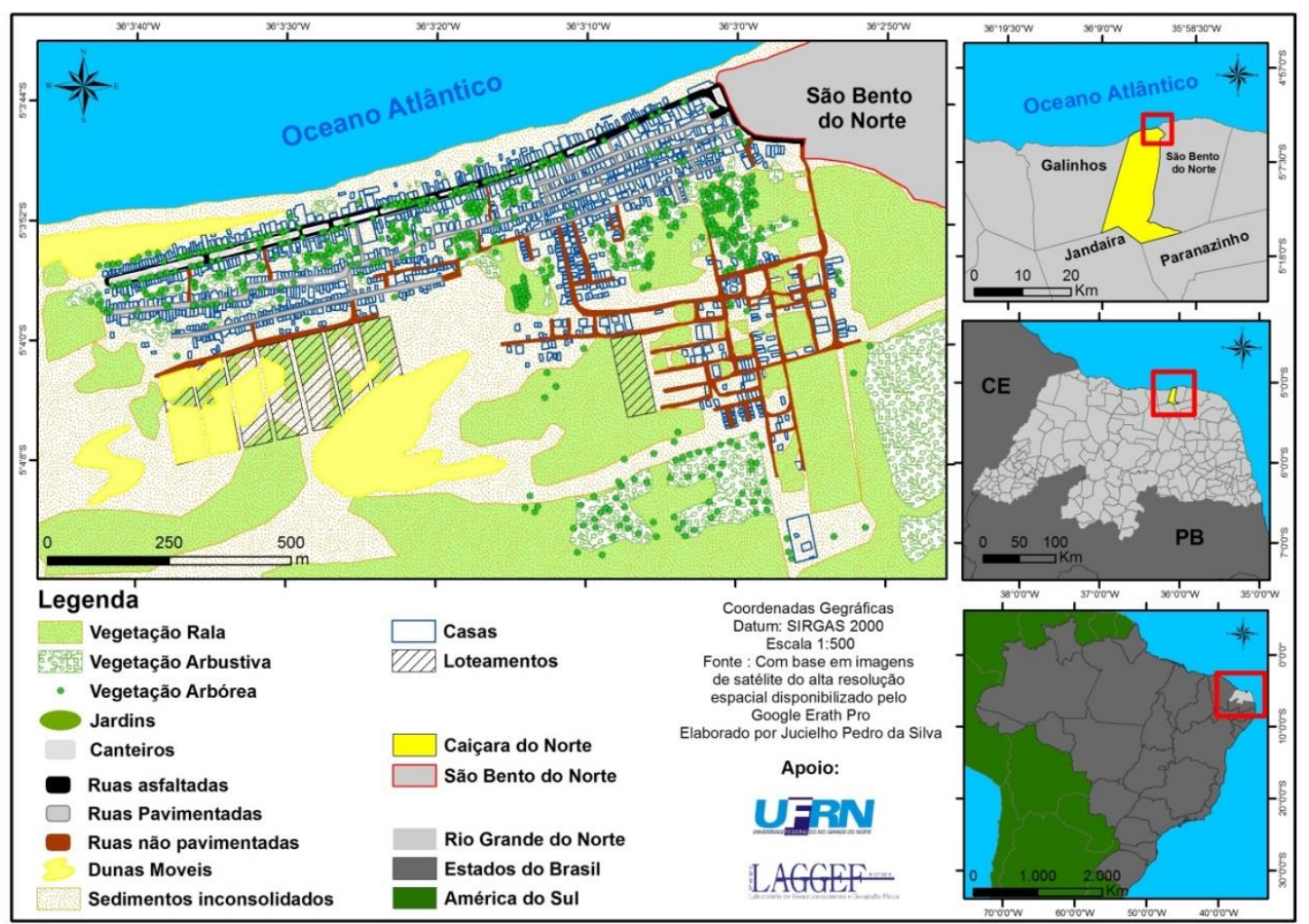

Figura 02. Planta baixa e mapa de localização do município de Caiçara do Norte/RN. Fonte: SILVA, J. P. (2016).

$\mathrm{Na}$ Figura 02 nota-se que as casas estão bem próximas do oceano e que a cidade foi instalada numa área de transpasse de dunas e sedimentos inconsolidados, local de forte influência da dinâmica costeira.

\section{METODOLOGIA}

A elaboração desse trabalho se deu em três etapas: $1^{\mathrm{a}}$ etapa levantamento bibliográfico a respeito de mudanças climáticas, mudanças de variação do nível do mar, previsões do IPCC e sobre a cidade de Caiçara do Norte, $2^{\mathrm{a}}$ etapa levantamento dos dados altimétricos em campo e a $3^{\mathrm{a}}$ etapa processamento dos dados e desenvolvimento da pesquisa em laboratório.

$\mathrm{Na}$ primeira etapa foi feito leitura em diversas fontes, dentre elas no site do IBGE sobre os aspectos demográficos da cidade em estudo, e nos relatórios do IPCC (2013; 2014), de onde foram adotadas as cotas altimétricas dos futuros níveis do mar que determinam que em 2100 a media global do nível do mar subirá entre $28 \mathrm{~cm}$ a $96 \mathrm{~cm}$ dependendo dos cenários.

$\mathrm{Na}$ segunda etapa foi feita a coleta dos dados topográficos in loco com uma estação total de marca Foif modelo OTS 680 com precisão de $\pm(2 \mathrm{~mm}+2 \mathrm{ppm} . \mathrm{D})$, contando com a ajuda dos bolsistas do LAGGEF (Laboratório de Geoprocessamento e Geografia Física) e os alunos da disciplina de Geografia do Mar do curso de Geografia do CERES/UFRN. Nesta etapa foram coletados 34 pontos topográficos cotados, ao longo da rua principal e adentrando nas ruas 
perpendicularmente a este perfil mais longo em direção ao mar e ao continente, formando um perfil em forma de degraus, como pode ser observado na figura 03.

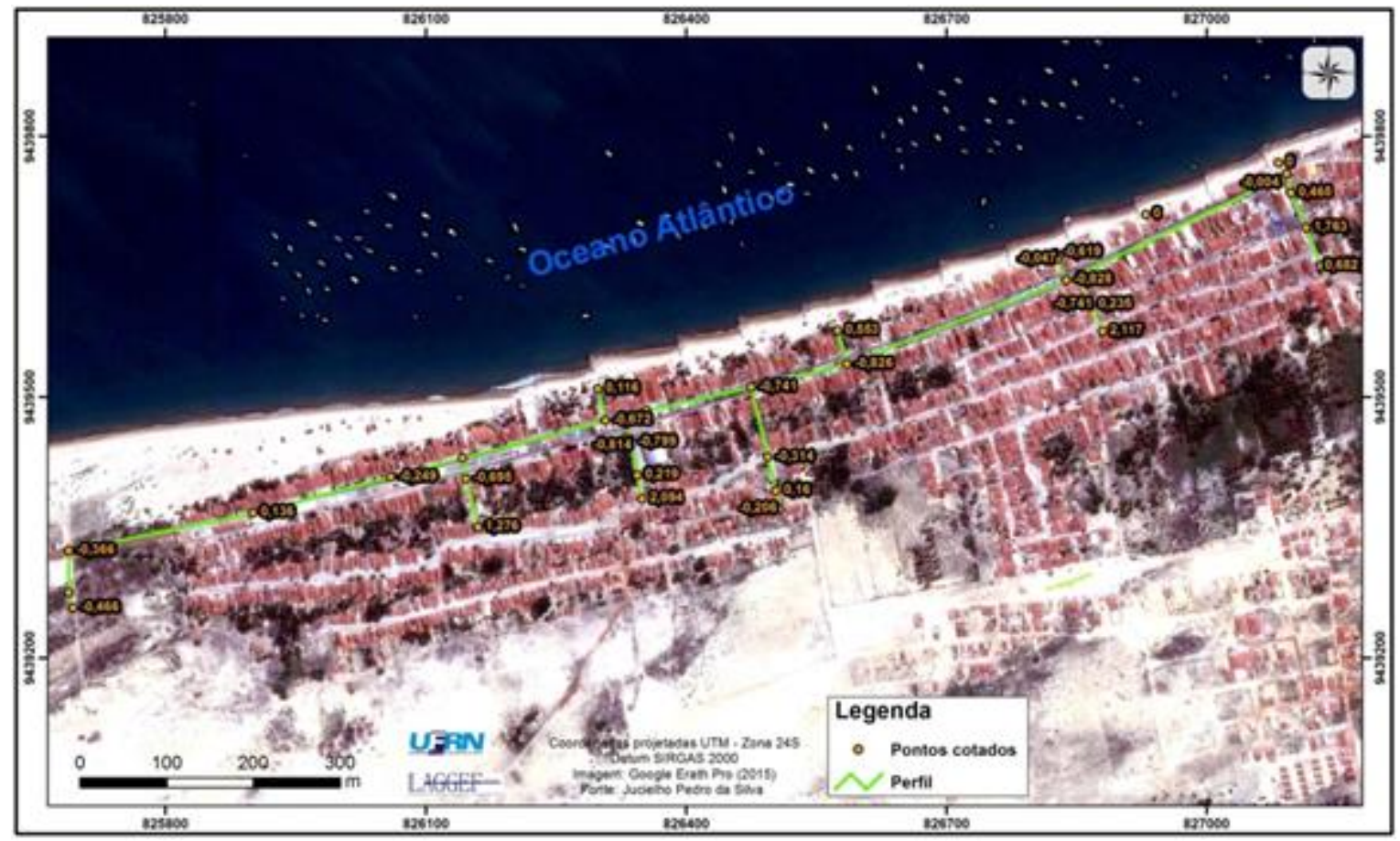

Figura 03. Mapa dos locais da coleta de pontos cotados na Caiçara do Norte/RN, 2015. Fonte: SILVA, J. P. (2016) com base nas imagens de satélite do Google Earth Pro 2016.

Este levantamento de campo realizou-se no dia 16/11/2015 com início por volta das 9h período em que a maré já estava recuando e tinha atingido $2.3 \mathrm{~m}$ de altura neste dia, segundo as previsões da tábua de maré da marinha do Brasil para o porto de Macau o mais próximo da cidade de Caiçara do Norte que fica a aproximadamente $65 \mathrm{Km}$.

$\mathrm{Na}$ terceira etapa foi feito o processamento dos dados utilizando-se o software GeoLink para a exportação dos dados da estação total para o computador e o software ArcGis 10.3 para fazer a interpolação dos pontos cotados que foram utilizados na geração dos mapas altimétricos. Foi realizado ainda o georreferenciamento de imagem de satélite do software Google Earth Pro, utilizada como base para a vetorização da planta baixa.

Dentre os vários tipos de interpolação testada, a utilizada e que melhor representou a realidade foi à interpolação Natural Neighbor (Vizinho Natural)

diferente das demais técnicas, esta não extrapola valores, resolvendo a interpolação somente para o interior do domínio dos dados. Esta técnica utiliza polígonos Thiessen para avaliação de pesos para os pontos. Este método faz a interpolação através da média ponderada dos pontos vizinhos, onde os pesos são proporcionais às áreas proporcionais. (MAZZINI; SCHETTINI, 2009, p. 58)

Ou seja, nesta técnica os pontos interpolados recebem o seu valor de acordo com o uma interpolação linear entre dos pontos cotados acrescido de um peso (ponderação) que é calculado 
proporcionalmente ao tamanho do seu polígono. Ver polígono de Thiessen de Alfred H. Thiessen. (MAZZINI; SCHETTINI, 2009).

\section{RESULTADOS E DISCUSSÃO}

As informações sobre altura da maré são de extrema importância para esta pesquisa, pois a cota zero (nível do mar) para este levantamento foi estipulada a partir da crista de berma deixada pela maré deste referido dia.

Cristas são feições geomorfológicas ou estruturais, continentais ou submarinas, formadas por elevação alongada de encosta mais ou menos abrupta e topo estreito. (SUGUIO, 1998, p. 189)

Crista de Berma (Berm crest) Limites rumo ao mar (seaward) de uma berma (berm) que, em geral representa a parte mais alta. (SUGUIO, 1998, p. 190)

Berma é a porção praticamente horizontal da praia (beach) ou pós-praia (backsshore) formada pela sedimentação por ação de ondas. (SUGUIO, 1998, p. 93)

Com a interpolação dos dados altimétricos foi possível gerar um MDT (Modelo Digital do Terreno) e partir disso o mapa hipsométrico (Figura 04) que representa a topografia do local e em seguida sobrepôs a planta baixa da zona urbana do município em estudo.

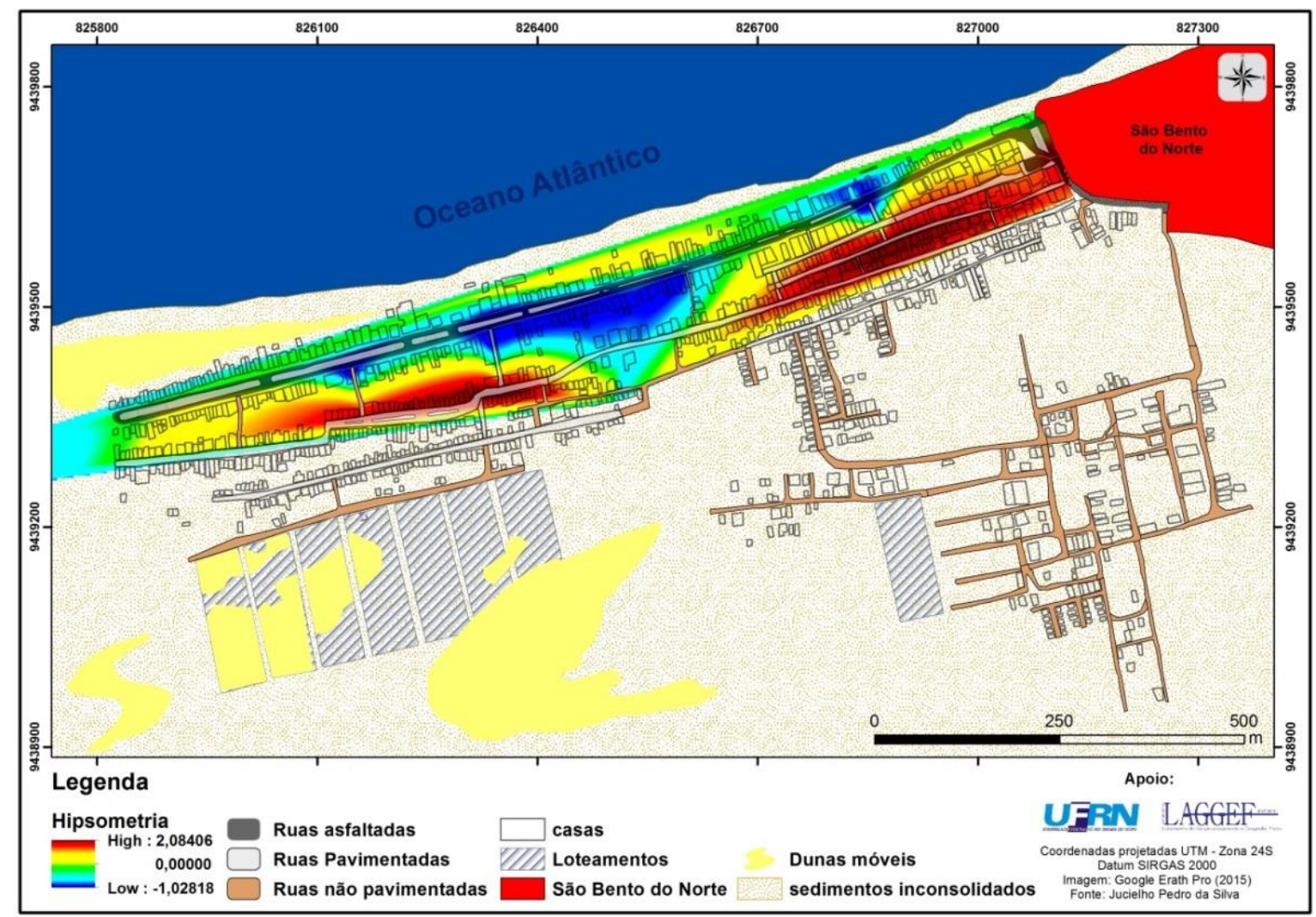

Figura 04. Mapa Hipsométrico da Zona Urbana de Caiçara do Norte/RN, 2015. Fonte: SILVA, J. P. 
Como pode visto nesta figura, atualmente a zona urbana da cidade encontra-se com uma parcela significativa abaixo da cota zero, protegido da invasão do oceano apenas pela crista de berma do cordão arenoso, visto na Figura 04 ao norte, nas cores em tons do verde ao amarelo.

Segundo Tabosa (2006) e Diniz (2013) esta região vem se tornando cada vez mais frágil a inundações, não só pela elevação do nível do mar, mas pela forte erosão e transgressão marinha, provocadas pela falta de sedimentos terrígenos os quais estão sendo barrados pelas edificações das zonas urbanas de Caiçara do Norte e São Bento do Norte, que em fluxos normais seriam remobilizados para área de estirâncio.

Frente a essas fragilidades surge mais um agravante a aceleração do aumento do nível do mar, os quais o relatório do IPCC 2013/2014 determina que em 2100 a média global do nível do mar subirá entre $28 \mathrm{~cm}$ a $96 \mathrm{~cm}$ dependendo dos cenários, como pode ser observado no Quadro 01.

\begin{tabular}{|l|c|c|c|c|c|}
\hline Year & SRES A1B & RCP2.6 & RCP4.5 & RCP6.0 & RCP8.5 \\
\hline 2007 & $0.03[0.02$ to 0.04$]$ & $0.03[0.02$ to 0.04$]$ & $0.03[0.02$ to 0.04$]$ & $0.03[0.02$ to 0.04$]$ & $0.03[0.02$ to 0.04$]$ \\
2010 & $0.04[0.03$ to 0.05$]$ & $0.04[0.03$ to 0.05$]$ & $0.04[0.03$ to 0.05$]$ & $0.04[0.03$ to 0.05$]$ & $0.04[0.03$ to 0.05$]$ \\
2020 & $0.08[0.06$ to 0.10$]$ & $0.08[0.06$ to 0.10$]$ & $0.08[0.06$ to 0.10$]$ & $0.08[0.06$ to 0.10$]$ & $0.08[0.06$ to 0.11$]$ \\
2030 & $0.12[0.09$ to 0.16$]$ & $0.13[0.09$ to 0.16$]$ & $0.13[0.09$ to 0.16$]$ & $0.12[0.09$ to 0.16$]$ & $0.13[0.10$ to 0.17$]$ \\
2040 & $0.17[0.13$ to 0.22$]$ & $0.17[0.13$ to 0.22$]$ & $0.17[0.13$ to 0.22$]$ & $0.17[0.12$ to 0.21$]$ & $0.19[0.14$ to 0.24$]$ \\
2050 & $0.23[0.17$ to 0.30$]$ & $0.22[0.16$ to 0.28$]$ & $0.23[0.17$ to 0.29$]$ & $0.22[0.16$ to 0.28$]$ & $0.25[0.19$ to 0.32$]$ \\
2060 & $0.30[0.21$ to 0.38$]$ & $0.26[0.18$ to 0.35$]$ & $0.28[0.21$ to 0.37$]$ & $0.27[0.19$ to 0.35$]$ & $0.33[0.24$ to 0.42$]$ \\
2070 & $0.37[0.26$ to 0.48$]$ & $0.31[0.21$ to 0.41$]$ & $0.35[0.25$ to 0.45$]$ & $0.33[0.24$ to 0.43$]$ & $0.42[0.31$ to 0.54$]$ \\
2080 & $0.44[0.31$ to 0.58$]$ & $0.35[0.24$ to 0.48$]$ & $0.41[0.28$ to 0.54$]$ & $0.40[0.28$ to 0.53$]$ & $0.51[0.37$ to 0.67$]$ \\
2090 & $0.52[0.36$ to 0.69$]$ & $0.40[0.26$ to 0.54$]$ & $0.47[0.32$ to 0.62$]$ & $0.47[0.33$ to 0.63$]$ & $0.62[0.45$ to 0.81$]$ \\
2100 & $0.60[0.42$ to 0.80$]$ & $0.44[0.28$ to 0.61$]$ & $0.53[0.36$ to 0.71$]$ & $0.55[0.38$ to 0.73$]$ & $0.74[0.53$ to 0.98$]$ \\
\hline
\end{tabular}

Quadro 01 Amplitude e média da elevação do nível do mar. Fonte: AR5, WG1, IPCC (2013).

De acordo com o quadro 01, na melhor das hipóteses os cientistas preveem um aumento do nível do mar de 0,28m no cenário RCP 2.6 (Representative Concentration Pathways) e na pior das hipóteses um aumento de $0,98 \mathrm{~m}$ no cenário RCP 8.5. Os cenários RCP podem ser melhor compreendido no site Skiptical Science < https://www.skepticalscience.com/rcp.php >

Entretanto, esses valores podem ser ainda maiores quando observados a nível regional ou local, pois dependendo do posicionamento geográfico, de eventos extremos (regimes de ventos e ondas) e efeitos estéricos (thermosteric and halosteric), alterações locais no volume de água decorrentes da temperatura e salinidade respectivamente, os valores se distanciam da média global em até $50 \%$ como pode ser visto na Figura 05. 


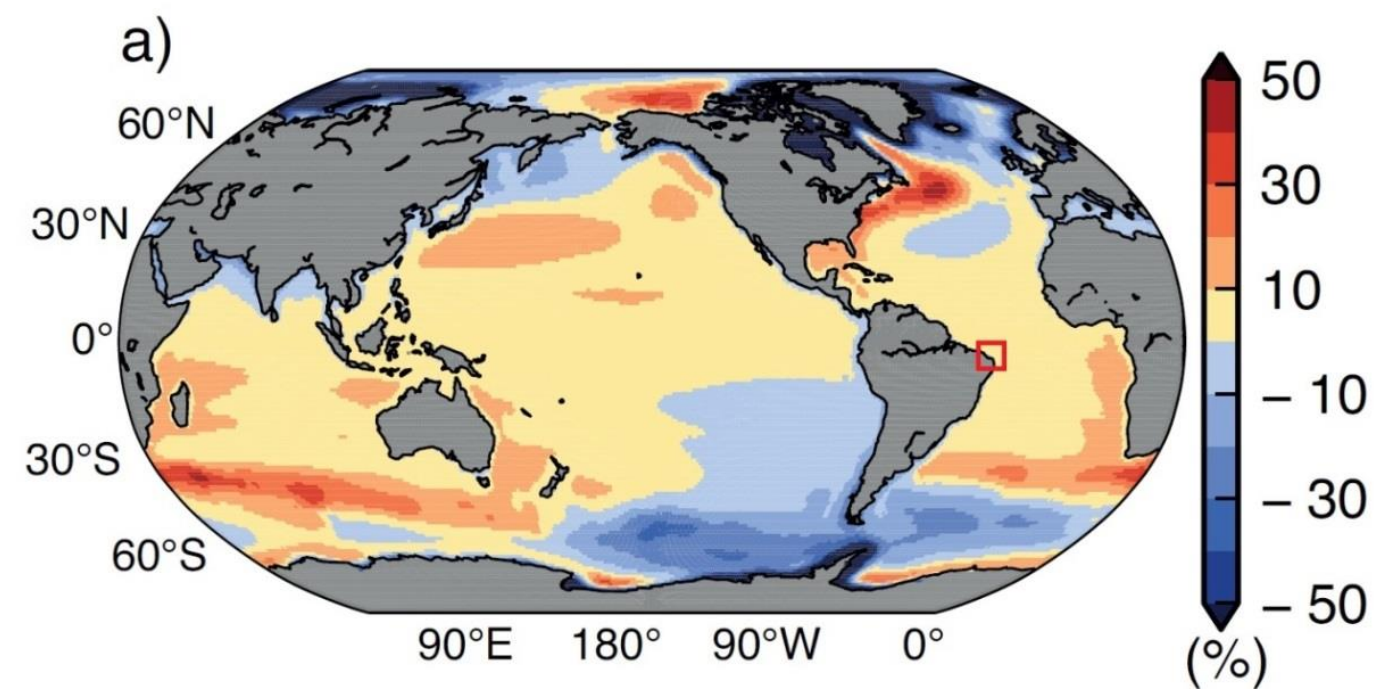

Figura 05. Globo representativo do desvio em relação à média global do aumento do nível do mar em (\%). Fonte: AR5, WG1, IPCC (2013). Adaptado pelo autor.

Com base nestas informações é possível perceber que a nível regional e municipal de Caiçara do Norte e regiões adjacentes poderão sofrer um aumento em 10\% do nível do mar além da média global. A partir disso, manipularam-se as classes altimétricas do mapa hipsométrico para simular as futuras cotas e áreas no terreno que em 2100 poderão estar imersas. (figura 06)

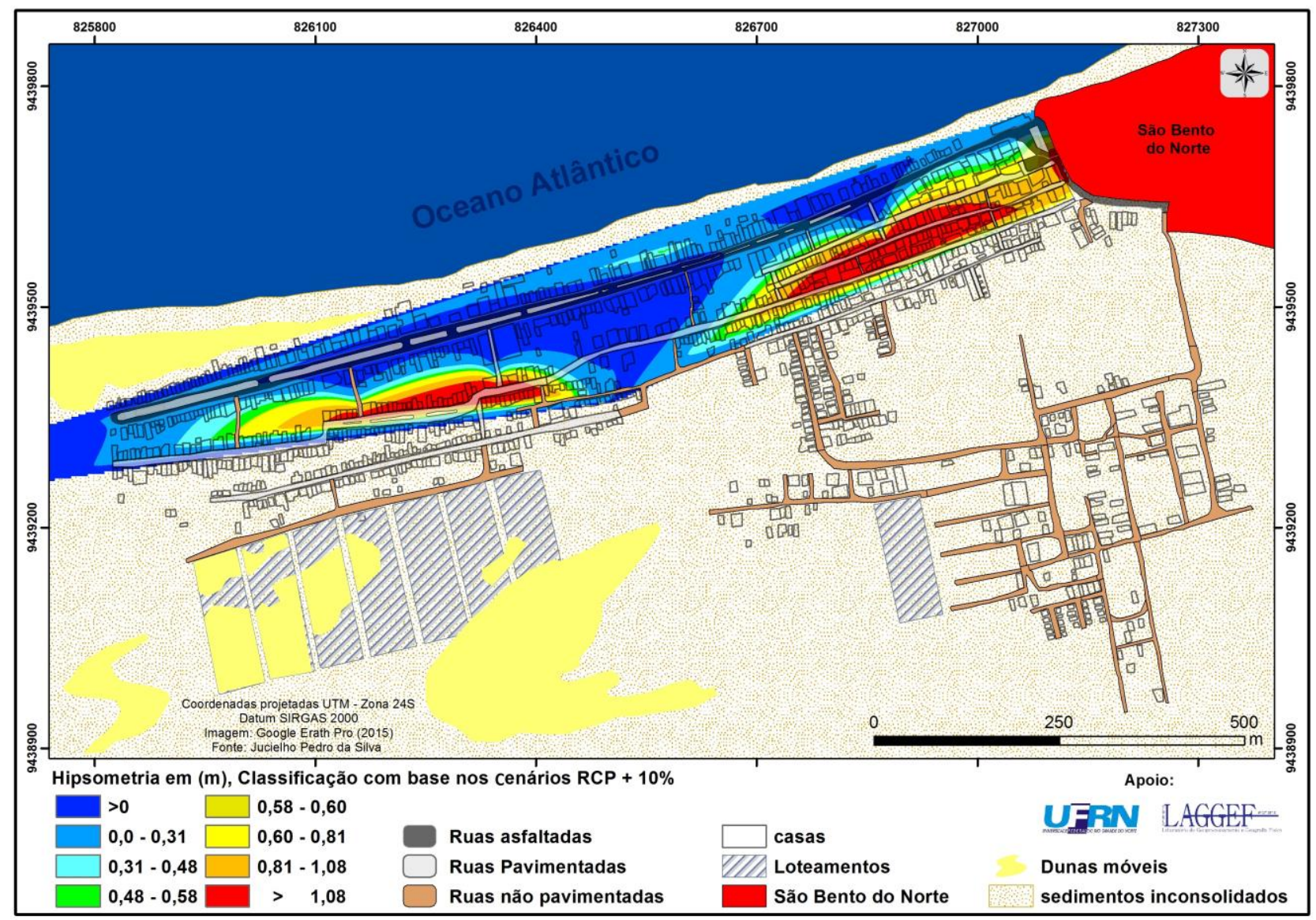

Figura 06. Mapa Hipsométrico da Zona Urbana de Caiçara do Norte/RN Classificado com base nos cenários do IPCC para 2100.

Fonte:

SILVA,

J. 
A classificação deste mapa foi feita com base nas médias previstas nos cenários RCP acrescido de $10 \%$, valor referente aos eventos extremos e efeitos estéricos dada à região, com exceção dos valores da primeira e a última classe, que são valores além da tabela, ou seja, o que esta abaixo do zero e o que esta acima do que mar esta previsto para atingir. Os valores da segunda e penúltima classe não os extremos, ou seja, o menor valor previsto que é $0,28 m+10 \%$ resultando na cota dos $0,31 \mathrm{~m}$ e o maior valor previsto que é $0,98 \mathrm{~m}+10 \%$ que resulta em $1,08 \mathrm{~m}$. As demais classes são a média mais $10 \%$ como pode ser visto, a terceira classe corresponde a média do senário RCP 2.8 que é $(0,44 m+10 \%=0,48 m)$ a quarta classe corresponde a média do senário RCP 4.5 que é $(0,53 \mathrm{~m}+10 \%=0,58 \mathrm{~m})$ a quinta classe corresponde a média do senário RCP 6.0 que é $(0,55 \mathrm{~m}+$ $10 \%=0,60 \mathrm{~m})$ e a sexta classe que corresponde a média do senário RCP 8.5 que é $(0,74 \mathrm{~m}+10 \%=$ $0,81 \mathrm{~m})$. Ressalta-se que os valores foram sempre arredondado uma casa decimal.

Como base neste mapa na figura 06 observou-se que em 2100 na melhor das hipóteses o mar ainda ultrapassará o cordão arenoso, impactando diretamente as casas da zona urbana de Caiçara do Norte, dos 646 imóveis construídos dentro do polígono de interpolação, apenas 125 imóveis $(19,3 \%)$ estão nas cotas acima do previsto pelos modelos do IPCC, ou seja, 521 imóveis (80,7\%) dentro da área de estudo poderão ser afetadas por inundações, sendo que na melhor das hipóteses, ou seja, no cenário mais otimista RCP 2.8 que prevê uma elevação média de 0,48m ainda afetará 383 imóveis $(40,7 \%)$ da área total em análise.

\section{CONSIDERAÇÕES FINAIS}

De acordo com esta pesquisa o município de Caiçara do Norte apresenta uma alta suscetibilidade à inundação, como está prevista para 2100 uma inundação de 40,7\% a 80,7\% da sua área urbana em estudo, salvo que o levantamento não cobre toda a área urbana do município. Isto se deve a dois fatores, primeiro ao fato das fortes erosões que vem sendo sofridas decorrentes das mudanças na dinâmica dos fluxos de matéria e energia, e segundo devido às mudanças climáticas globais que provocarão um aumento no nível do mar. Aumento este que na melhor das hipóteses ultrapassará a cota altimétrica da crista de berma do cordão arenoso que protege as áreas da cidade onde atualmente já se encontra abaixo do nível do mar.

Sendo assim, esta pesquisa contribui para o ordenamento e gerenciamento costeiro desta região, pois traz à tona uma temática de alta relevância, fornecendo informações a respeito de como se encontra atualmente a região frente à temática de elevação do nível do mar e como será em 2100, alertando os responsáveis a tomarem medidas mitigadoras preventivas.

\section{REFERÊNCIAS}


BITENCOURT, Daniel Pires; QUADRO, Mário F. Leal de; CALBETE, Nuri O. de. Análise de dois casos de ressaca no litoral da região sul no verão de 2002. In: xii congresso brasileiro de meteorologia, 12., 2002, Foz de Iguaçu. Anais do XII Congresso Brasileiro de Meteorologia. Foz de Iguaçu: Sbmet, 2002. p. 3910 - 3917.

BIVAR, Wasmália; MOURA NETO, Julio Soares de. Atlas geográfico das zonas costeiras e oceânicas do Brasil. Rio de Janeiro: Ibge, 2011.

DINIZ, Marco Túlio Mendonça. CONDICIONANTES SOCIOECONÔMICOS E NATURAIS PARA A PRODUÇÃO DE SAL MARINHO NO BRASIL: AS PARTICULARIDADES DA PRINCIPAL REGIÃO PRODUTORA. 2013. 227 f. Tese (Doutorado) - Curso de Geografia, Universidade Estadual do Ceará, Fortaleza, 2013.

IPCC, 2013: Climate Change 2013: The Physical Science Basis. Contribution of Working Group I to the Fifth Assessment Report of the Intergovernmental Panel on Climate Change [Stocker, T.F., D. Qin, G.-K. Plattner, M. Tignor, S.K. Allen, J. Boschung, A. Nauels, Y. Xia, V. Bex and P.M. Midgley (eds.)]. Cambridge University Press, Cambridge, United Kingdom and New York, NY, USA, $1535 \mathrm{pp}$.

JOHN A. CHURCH; PETER U. CLARK (United States Of America). Ipcc (Org.). Sea Level Change. In: IPCC (USA). Intergovernmental Panel On Climate Change (Org.). Climate Change 2013: The Physical Science Basis. New York: Cambridge University Press, 2013. Cap. 13. p. 1137 1201.

MAZZINI, P. L. F.; SCHETTINI, Carlos Augusto França. Avaliação de metodologias de interpolação espacial aplicadas a dados hidrográficos costeiros quase-sinóticos. Braz. J. Aquat. Sci. Technol., [s.1.], v. 13, n. 1, p.53-64, 17 jul. 2009. Editora UNIVALI. http://dx.doi.org/10.14210/bjast.v13n1.p53-64.

POH POH WONG; IÑIGO J. LOSADA. Ipcc (Org.). Coastal Systems and Low-Lying Areas. In: IPCC (USA). Intergovernmental Panel On Climate Change. Climate Change 2014 Impacts, Adaptation, and Vulnerability Part A: Global and Sectoral Aspects. New York: Cambridge University Press, 2014. Cap. 5. p. 361-409.

SUGUIO, Kenitiro. Dicionário de geologia sedimentar e áreas afins. Rio de Janeiro: Bertrand Brasil, 1998. 1222 p.

TABOSA, Werner Farkatt. Monitoramento costeiro das praias de são Bento do norte e caiçara do norte - rn: Implicações para o pólo petrolífero de Guamaré. 2002. 147 f. Dissertação (Mestrado) Curso de Geodinâmica e Geofísica, Universidade Federal do Rio Grande do Norte, Natal, 2006.

\section{AGRADECIMENTOS}

Gostaria de deixar aqui minha gratidão para todos que contribuíram para o desenvolvimento desta pesquisa, dentre eles: Prof. Dr. Marco Tulio Mendonça Diniz, Dr. Clistenes Teixeira Batista, Dr. Werner Farkatt Tabosa, George Oliveira, Diogo Bernardino, Halison Almeida, Isa Gabriela, Luana Mariz, Camila Cristina e Julia Azevedo. Agradeço também a UFRN (Universidade Federal do Rio Grande do Norte) e ao LAGGEF (Laboratório de Geoprocessamento Geografia Física).

Recebido em: 14/08/2016

Aceito para publicação em: 01/10/2016 